\title{
A PLEBE E A SUA CONSTITUIÇÃO: O QUE HEGEL E MARX TÊM A NOS DIZER SOBRE O POPULISMO?
}

\author{
Emmanuel Nakamura ${ }^{1}$
}

Ao Marcos Müller

\begin{abstract}
Resumo:
Nos últimos anos, a crítica à dinâmica de mercado capitalista e a questão da pobreza ganharam um espaço dentro dos estudos hegelianos. No debate público, assistimos hoje em dia a uma crescente preocupação com o fenômeno do populismo. O objetivo do meu artigo é encontrar elementos para uma caracterização do novo populismo a partir da consideração de Hegel sobre a plebe. De acordo com Hegel, a geração da plebe é o resultado da dinâmica antagônica da economia de mercado liberalizada. A passagem da sociedade civil burguesa ao Estado se apoia na base precária da formação da disposição de ânimo política a favor do Estado. Esta provém do bem-estar particular legalmente reconhecido e realizado como direito através da dupla mediação do político entre as instituições sociais e a representação política. A plebe assinala uma perturbação dessa dinâmica de reconhecimento, pois ela não está organizada nos círculos particulares das instituições da sociedade civil. Isso traz consequências negativas para o estado de direito: por um lado, a atuação do governo não pode ser controlada de baixo para cima e, por outro, a plebe desenvolve uma disposição de ânimo contra o governo e as instituições do estado de direito.
\end{abstract}

Palavras-chave: Plebe. Pobreza. Mercado capitalista. Representação política.

\section{THE RABBLE AND ITS CONSTITUTION: WHAT DO HEGEL AND MARX HAVE TO SAY US ABOUT POPULISM?}

\begin{abstract}
:
In the last years, the criticism of the capitalist market dynamic and the question of poverty have gained a space within Hegelian studies. In the public debate we are seeing an increasing concern about the phenomenon of populism. The aim of my paper is to find out elements for a characterization of the new populism in Hegel's description about the rabble. According to Hegel, the generation of the rabble is the result of the antagonistic dynamic of a liberalized market economy. The transition of bourgeois civil society to the state is based on the precarious basis of the formation of the political disposition. This arises from the particular welfare that is legally recognized and realized as a right through the double mediation of the political between social institutions and political representation. The rabble accentuates a disturbance in this dynamic of recognition, since it is not organized in the particular circles of civil society institutions. This has negative consequences for the constitutional state: on the one hand, government action cannot be controlled from below, and on the other hand, the rabble develops a disposition against the government and the institutions of the constitutional state.
\end{abstract}

Keywords: Rabble. Poverty. Capitalist market. Political representation.

1 Doutor em Filosofia pela Humboldt-Universität zu Berlin, pós-doutorando na Universidade de Campinas (UNICAMP) e autor do livro Der Maßstab der Kritik des modernen Staates bei Hegel und Marx. Der Zusammenhang zwischen subjektiver und sozialer Freiheit (Berlin: De Gruyter, 2018, Hegel-Jahrbuch, Sonderband 12). Contato: el.nakamura@daad-alumni.de. 


\section{Introdução}

Nos últimos anos, a discussão sobre o populismo tomou conta do debate público. Esta foi animada pelo surgimento de governos como os de Putin, Erdoğan, Orbán, Johnson, Trump, Bolsonaro e etc. No espaço acadêmico, os cientistas políticos têm ganhado notabilidade pela defesa das democracias liberais contra a emergência do populismo de extremadireita. No âmbito político, o neoliberalismo progressivo e a esquerda liberal formam uma única voz em defesa das liberdades públicas. Alguns intelectuais de esquerda, no entanto, não veem apenas retrocessos nesse novo populismo e preferem desenvolver uma "razão populista” (LACLAU, 2005). Em meu artigo, eu não pretendo entrar a fundo nesse debate e nem mesmo retomar discussões anteriores sobre populismo que remetem a outros períodos históricos. Apenas tomo de Laclau (2005, p. 206) a definição de populismo como "o terreno de uma indecibilidade primária entre a função hegemônica do significante vazio e a equivalência de demandas particulares.” Meu objetivo é tão somente encontrar elementos para uma caracterização do novo populismo a partir da consideração de Hegel sobre a plebe. Minha hipótese é que tanto a plebe descrita por Hegel como o novo populismo têm em comum um caráter antiinstitucional, que se volta contra um dos pilares da ideia de Estado moderno e das sociaisdemocracias do pós-guerra - i.e. a dupla mediação do político entre instituições sociais e representação política. A dissolução dessa mediação cria uma forma de fazer política baseada na maneira de ver da plebe.

Além de Laclau (2005), meu ponto de partida e chegada para caracterizar o novo populismo são as análises de Fukuyama (2018) e Mounk (2018). De maneira polêmica, Fukuyama procura aproximar as políticas identitárias, associadas ao neoliberalismo progressista e à esquerda liberal, da política populista de extrema-direita. ${ }^{2}$ Os dois lados teriam em comum o fato de suas políticas se apoiarem em formas de sentimentos de autoestima decorrentes das narrativas de experiências vividas. Uma experiência vivida particular forma uma identidade que precisa ser reconhecida como direito ou como política pública. Da mesma forma, a assim chamada classe trabalhadora branca norte-americana exige o reconhecimento de sua experiência de vida. A perturbação dessa dinâmica de reconhecimento gera ressentimentos. Já

\footnotetext{
2 "What is notable, however, is how the right has adopted the language and framing of identity from the left: the idea that my particular group is being victimized, that its situation and sufferings are invisible to the rest of society, and that the whole of the social and political structure responsible for this situation (read: the media and political elites) needs to be smashed. Identity politics is the lens through which most social issues are now seen across the ideological spectrum." (FUKUYAMA, 2018, p. 165).
}

\begin{tabular}{|l|l|l|l|l|}
\hline Q Rovista Dialectus & Ano 9 & n. 18 & Outubro 2020 & p. 365-389 \\
\hline
\end{tabular}


Mounk defende que as democracias liberais estão se decompondo em duas partes. De um lado, temos o surgimento de democracias iliberais, isto é, sem direitos civis, e, de outro, de liberalismos não-democráticos, responsáveis por um "disempowerment" do povo, por meio de instituições tecnocráticas e uma elite econômica (2018, p. 93). Para o Fukuyama (2018, p. 215), o fracasso na procura pelo reconhecimento de uma identidade autêntica da experiência vivida faz a formação da vontade política dos Estados modernos se apoiar em dois polos: por um lado, há indivíduos à procura de autoestima por meio do reconhecimento da dignidade de experiências vividas e, com isso, expostos a lideres populistas, que, por outro lado, conseguem mobilizar o ressentimento gerado pelo fracasso dessa demanda por reconhecimento. ${ }^{3}$ Mounk (2018, p. 35), por sua vez, nos lembra que essa frustração se volta contra as instituições intermediárias das democracias liberais.

Em meu artigo, eu não pretendo discutir as soluções propostas pelos dois autores, mas sim apenas articular esses diagnósticos por meio de uma reconstituição das causas do surgimento da plebe dentro filosofia do direito de Hegel e uma interpretação de seus efeitos políticos. O meu texto está dividido em 5 partes. Na primeira, eu pretendo mostrar como o surgimento da plebe se assenta em uma dinâmica antagônica de funcionamento da sociedade de mercado capitalista (1). Na segunda parte, eu mostro o papel desempenhado pela dupla mediação do político, entre as instituições sociais e a representação política, para a formação da disposição de ânimo a favor do estado de direito (2). Em seguida, eu teço algumas considerações sobre a resposta do jovem Marx à questão social do Vormärz com o intuito de mostrar a alternativa à emergência da plebe - i.e. a formulação e integração dos interesses particulares da classe despossuída dentro do estado de direito (3). Na quarta parte, eu discuto uma contradição da dinâmica de funcionamento da democracia representativa: por um lado, ela permite que o debate político, o reconhecimento e a realização do bem-estar particular na forma de direitos sociais cheguem até a classe despossuída; por outro lado, a formação da vontade política democrática abstrai das instituições mediadoras, minando as condições de seu próprio funcionamento (4). Por fim, eu procuro apontar como a desinstitucionalização do tecido social põe o arbítrio da vontade privada como a única base para a formação da política de governo (5).

\footnotetext{
3 "The authentic identities they are seeking are ones that bind them to other people. They can be seduced by leaders who tell them that they have been betrayed and disrespected by the existing power structures, and that they are members of important communities whose greatness will again be recognized." (FUKUYAMA, 2018, p. 215).
}

\begin{tabular}{|l|l|l|l|l|}
\hline Q Revista Dialectus & Ano 9 & n. 18 & Outubro 2020 & p. 365-389 \\
\hline
\end{tabular}




\section{A dinâmica antagônica da sociedade de mercado capitalista}

Para Hegel, o "direito da particularidade do sujeito", ou o "direito da liberdade subjetiva", "constitui o ponto de virada e o ponto central na diferença entre a Antiguidade e os Tempos Modernos."4 (GW 14,1: § 124 A.) Ou seja, Hegel afirma, com isso, que a liberdade individual é o princípio, ou o valor, constituinte da modernidade. A liberdade individualsubjetiva se assenta na separação entre sociedade civil burguesa e Estado, pois a separação significa que o sujeito tem o direito de "encontrar-se satisfeito" (GW 14,1: § 124 A.), isto é, de buscar livremente a satisfação de suas carências e seus interesses particulares. Em outras palavras, a separação significa que, na modernidade, os interesses particulares não formam imediatamente o interesse coletivo. Os elementos particulares e comunitários se apresentam em duas esferas separadas institucionalmente - a sociedade civil burguesa e o Estado.

A separação não significa, no entanto, que a sociedade civil burguesa seja apenas uma coleção de carências e interesses particulares. O âmbito comunitário está presente de três maneiras: (1) o direito da liberdade subjetiva surge, historicamente, como um princípio do espírito do mundo trazido à existência pelo cristianismo (GW 20: § 482 A.); (2) o direito da particularidade subjetiva tem um caráter "universalmente válido", no sentido de que o agir individual, orientado para satisfazer o próprio bem-estar particular, "se determina segundo leis e princípios pensados, isto é, universais" - o direito, como forma universalmente válida, constitui o "ponto de partida" e o "resultado", condicionando as "modalidades de comportamento" na busca pela satisfação particular (GW 14,1: § 258 A.); (3) a efetivação de um fim egoísta está condicionada por um "sistema de dependência omnilateral”, ou seja, por um espaço social-comunitário onde se desenvolvem as relações de mercado (GW 14,1: § 183). É por isso que a recepção norte-americana de Hegel criou a definição de liberdade social, no sentido de que as liberdades individuais só podem ser conquistadas socialmente, ou seja, por meio da participação em instituições sociais. ${ }^{5}$

Cito as obras de Hegel a partir das edições críticas por meio da sigla GW (Gesammelte Werke) e indicação do volume. No caso das Linhas fundamentais da filosofia do direito, indico parágrafo e em seguida, quando for o caso, a sigla A (Anotação). Utilizo a tradução de Marcos Müller, eventualmente com alguma modificação. As outras traduções de textos de Hegel são de minha autoria.

5 " [...] this conception of freedom is particularly difficult to grasp, in part because it is both a freedom that individuals achieve through certain ways of participating in their social institutions and a freedom that can be predicated of those institutions themselves, insofar as they are rational." (NEUHOUSER, 2000, p. 5)

\begin{tabular}{|c|c|c|c|c|}
\hline Qonista Dialectus & Ano 9 & n. 18 & Outubro 2020 & p. $365-389$ \\
\hline
\end{tabular}


Enquanto forma socialmente válida de realização da liberdade individual, o direito é o ser-aí da vontade livre (GW 14,1: § 29). Para Hegel, as liberdades modernas só podem ser realizada racionalmente como direito. Mas só se pode criar e organizar instituições que realizem as liberdades individuais quando a liberdade individual se torna um princípio, ou um valor, que norteia nossas ações e a criação e uso de instituições. A ideia da vontade livre é a formulação filosófica desse valor que veio ao mundo por meio do cristianismo - mais especificamente, por meio do protestantismo. Isso não significa que a ideia de Estado livre de Hegel é fundada religiosamente. No protestantismo, Hegel tem apenas o ancoramento histórico da consciência que reconhece a "diferenciação da forma da autoridade e da fé", de modo que a separação entre Estado e confissão religiosa surge de baixo para cima, "na medida em que o lado eclesial chega em si mesmo à separação"6 (GW 14,1: § 270 A.). Este é o ponto de partida histórico para que o Estado possa adquirir a forma laica da "universalidade do pensamento", “acima das igrejas particulares" (GW 14,1: § 270 A.).

Diante do mundo exterior, a ideia da vontade livre é um princípio abstrato de reconstituição das relações sociais e políticas. A forma universalmente válida do direito aparece, inicialmente, como abstração de qualquer contexto, isto é, como direito abstrato. Independentemente de qualquer situação, os indivíduos são pessoas livres. Essa abstração confere à personalidade jurídica uma capacidade, pois a abstração do direito é o solo comum que retira o indivíduo de qualquer relação de dependência e dominação, permitindo que a pessoa se relacione apenas consigo mesmo em sua liberdade ( $\mathrm{GW}$ 14,1: § 35). A capacidade jurídica confere à pessoa uma propriedade tanto do ponto de vista interno como também externo: enquanto pessoa livre, eu sou proprietário de minhas próprias capacidades e também sou livre para adquirir propriedade. $^{7}$ - Por isso não me parece correta a interpretação de Schildbach (2018, p. 262), que localiza na instituição do direito privado o "começo do problema da pobreza". A abstração, ou a "ignorância", do direito privado em relação à satisfação das carências particulares significa que a pessoa se relaciona com o mundo exterior apenas pela mediação da vontade livre, desnaturalizando qualquer relação de posse, dependência e dominação. A possibilidade da existência de uma propriedade comum não é negada pela instituição do

6 "Für den Hegel der späten 1820er Jahre ist ein freier Staat ein protestantischer Staat, und zwar nicht, weil der Protestantismus geeignet wäre, den Staat zu fundieren, sondern umgekehrt: weil der protestantische Staat kein religiös fundierter Staat ist, sondern die Sittlichkeit des Staates als eine Gestalt eigenen Rechtes anerkennt - also weil er anerkennt, dass der Staat keiner Fundierung durch eine explizite Religion bedarf, sondern sein Fundament in sich selber hat." (JAESCHKE, 2009, p. 15 et seq.).

7 "La personne peut être définie comme un pur rapport de la liberté à elle-même, s'exprimant comme un rapport indéfini, et en ce sens formel, entre elle et les choses." (KERVÉGAN, 2007, p. 62).

\begin{tabular}{|c|c|c|c|c|}
\hline Rovista Dialectus & Ano 9 & n. 18 & Outubro 2020 & p. $365-389$ \\
\hline
\end{tabular}


direito abstrato, mas a sua existência está sujeita ao arbítrio de cada pessoa (GW 14,1: § 46). Por um lado, nem tudo é passível de virar propriedade privada: "A particularidade de objetos elementares, segundo a sua natureza, não é possível de ser particularizada como propriedade privada". Por outro lado, "as determinações que concernem à propriedade privada podem ser subordinadas às esferas mais altas do direito" (GW 14,1: § 46 A.).

Além disso, Hegel caracteriza a dinâmica de mercado como um "sistema de carências" mediado pelo trabalho $(\mathrm{GW} 14,1: \S 188)$. No trabalho, reside o "momento da libertação" (GW 14,1: § 194 A.), no sentido de um "momento social”, ou de socialização por meio do trabalho, pois por meio dele as carências imediatas ou naturais se tornam carências sociais (GW 14,1: § 194). Essa libertação do trabalho é, porém, apenas formal, já que "a particularidade dos fins permanece o conteúdo que lhe serve de fundamento" (GW 14,1: § 195). O trabalho é a "mediação que consiste em preparar e obter para as carências particularizadas meios adequados, igualmente particularizados" (GW 14,1: § 196). Há no trabalho um elemento "universal e objetivo", presente na "abstração do produzir", que "efetua a especificação dos meios e das carências" (GW 14,1: 198), mas os "múltiplos fins" atingidos pela mediação objetiva do trabalho permanecem ligados a um "material imediatamente fornecido pela natureza." (GW 14,1: § 196). Em suma, a abstração da propriedade privada não pode ser totalmente indiferente em relação à satisfação das carências naturais e sociais. ${ }^{8}$

No entanto, a possibilidade de participação na riqueza social, como forma de satisfação de uma carência particular, está condicionada a circunstâncias contingentes que ligam um indivíduo à posse de capital ou a uma determinada capacidade de trabalho $(\mathrm{GW} 14,1$ : $\S$ 200). O sistema de carências está organizado por um sistema de trocas em que cada indivíduo aliena a sua mercadoria, fruto do seu trabalho, com o objetivo de adquirir a mercadoria de outro indivíduo e, com isso, satisfazer a sua própria carência: “As carências e os meios, enquanto ser-aí real, tornam-se um ser para outros, por cujas carências e por cujo trabalho a satisfação está reciprocamente condicionada.” (GW 14,1: § 192) O que move o sistema de trocas é o "egoísmo subjetivo", pois cada um quer satisfazer a sua própria carência por meio da mercadoria de outro, mas, para isso, cada um precisa alienar o produto do seu próprio trabalho e, dessa maneira, cada um contribui "para a satisfação das carências de todos os ou-

8 “[...] Arbeit ist ihrem Begriff nach Vermittlung, gegenständliche Beziehung, in der das Subjekt sich noch immer auf ein Anderes bezieht. An ihr klebt das Naturhafte, Empirische, Endliche, während Hegel in letzter Konsequenz das Absolute als eine reine Subjektivität denken will, die sich nur auf sich selbst bezieht und nicht mehr mit einem Anderen behaftet ist.” (ARNDT, 2001, p. 103 et seq.)

\begin{tabular}{|l|l|l|l|l|}
\hline Q Povista Dialectus & Ano 9 & n. 18 & Outubro 2020 & p. 365-389 \\
\hline
\end{tabular}


tros": "cada um adquire, produz e frui por si, precisamente com isso produz e adquire para a fruição dos demais.” (GW 14,1: § 199) A satisfação de uma carência particular é mediada por um elemento universal, um processo de socialização, mas a satisfação da carência social geral não se apresenta como um fim para cada indivíduo. ${ }^{9}$ Ela é o resultado da "dependência e reciprocidade do trabalho e da satisfação das carências", isto é, do "entrelaçamento da dependência de todos por todos os lados" (GW 14,1: § 199).

Esse entrelaçamento implica em uma divisão social do trabalho. A satisfação de carências particularizadas exige meios particularizados de trabalho e uma formação prática pelo trabalho. Por meio desse processo, o trabalho se restringe de três maneiras: (1) "segundo a natureza do material"; (2) "segundo o arbítrio dos outros"; e (3) segundo o "hábito que se adquire por essa disciplina de exercer atividade objetiva". A especialização do trabalho não anula o seu caráter de "ocupação em geral", ou seja, o fato de que as atividades do trabalho precisam corresponder a "habilidades universalmente válidas" (GW 14,1: § 197), para satisfazer as carências sociais. ${ }^{10}$ Contudo, justamente, na abstração do trabalho reside uma contradição: se por um lado ela permite a especificação dos meios e das carências, por outro, ao permitir a divisão das tarefas, "o trabalho do singular torna-se mais simples", "mais mecânico", de modo que o homem pode ser retirado do processo produtivo e seja substituído por máquinas (GW 14,1: § 198). Por um lado, o trabalho é o meio universal para adquirir parte da riqueza social; por outro lado, a própria organização social da produção subtrai dos indivíduos os meios naturais de aquisição da riqueza social (GW 14,1: § 241).

A dinâmica de mercado oferece, portanto, apenas a mera "possibilidade" para "a subsistência e o bem-próprio de cada singular", enquanto a "efetividade" da participação na riqueza social está condicionada pelo caráter arbitrário, pelo elemento natural e pela objetividade da organização do sistema de carências (GW 14,1: § 230). A dinâmica liberalizada de mercado oferece tanto a possibilidade de participação na riqueza social como o risco de "reduzir os indivíduos à pobreza" (GW 14,1: § 241). Em sua "atuação desimpedida”, a sociedade de mercado possui uma dinâmica antagônica: por um lado, ela universaliza a "conexão entre

9 “Das allgemeine Interesse ist eben die Allgemeinheit der selbstsüchtigen Interessen.” (MEGA II,1.1: p. 168). Cito as obras de Marx a partir das edições críticas por meio da sigla MEGA (Marx-Engels-Gesamtausgabe), com indicação da seção e do volume.

10 "Sie müssen einerseits als bestimmte nützliche Arbeiten ein bestimmtes gesellschaftliches Bedürfniß befriedigen und sich so als Glieder der Gesamtarbeit, des naturwüchsigen Systems der gesellschaftlichen Theilung der Arbeit, bewähren. Sie befriedigen andrerseits nur die mannigfachen Bedürfnisse ihrer eignen Producenten, sofern jede besondre nützliche Privatarbeit mit jeder andren nützlichen Art Privatarbeit austauschbar ist, also ihr gleichgilt." (MEGA II,10: p. 73).

\begin{tabular}{|l|l|l|l|l|}
\hline Qevista Dialectus & Ano 9 & n. 18 & Outubro 2020 & p. 365-389 \\
\hline
\end{tabular}


os homens" e "aumenta a acumulação das riquezas"; por outro, ela "aumenta o isolamento e o caráter restrito do trabalho particular e, com isso, a dependência e a penúria da classe atada a esse trabalho"11 (GW 14,1: § 243). Essa "grande massa" pobre - ao decair "abaixo do padrão de um certo modo de subsistência" (GW 14,1: § 244) - se torna incapaz de "sentir e de fruir as demais liberdades e, particularmente, as vantagens espirituais da sociedade civil." (GW 14,1: § 243). O "sentimento de injustiça" - decorrente da perda das "vantagens da sociedade", da "capacidade de adquirir habilidades e cultura em geral, [...] assistência jurídica, [...] cuidado da saúde e até mesmo, muitas vezes, o consolo da religião" - é responsável pela “disposição de ânimo da aversão ao trabalho, da malignidade e de outros vícios” (GW 14,1: § 241). A "plebe" (Pöbel) se caracteriza pela perda do "sentimento de direito, da retidão e da honra de subsistir mediante atividade própria e trabalho próprio"12 (GW 14,1: § 244).

Hegel não possui uma solução definitiva para essa questão social e se limitou a constatar que, "no seu excesso de riqueza, a sociedade civil não é suficientemente rica [...] para obviar ao excesso de pobreza e à geração da plebe" (GW 14,1: § 245). Entretanto, ele não deixa de localizar uma tendência: "o esforço da sociedade vai na direção de descobrir e organizar o que há de universal na miséria e no socorro a ela e a tornar aquela ajuda dispensável." (GW 14,1: § 242) - Ou seja, uma resposta à questão social passa por um "esforço da sociedade" em "descobrir e organizar o que há de universal na miséria".

\section{A disposição de ânimo para o estado de direito}

A especificação e multiplicação de carências e o desenvolvimento da divisão do trabalho acompanham o desenvolvimento de uma "formação teórica" do trabalho, com sua "multiplicidade de representações e conhecimentos", e a "formação do entendimento em geral, por conseguinte, também a da linguagem." (GW 14,1: § 197) A divisão social do trabalho cria, portanto, ramos (ou estamentos) específicos de trabalho, com formas de vida particula-

${ }^{11}$ É claro que Marx teria muito mais a acrescentar sobre esse caráter antagônico da produção e acumulação capitalista: "Die Akkumulation von Reichthum auf dem einen Pol ist also zugleich Akkumulation von Elend, Arbeitsqual, Sklaverei, Unwissenheit, Brutalisierung und moralischer Degradation auf dem Gegenpol, d.h. auf Seite der Klasse, die ihr eignes Produkt als Kapital produciert.” (MEGA II,10: p. 580).

12 Para Ruda (2011, p. 76), não é a pobreza em si, mas essa perda do sentimento de direito que, fundamentalmente, caracteriza a plebe. Tanto a miséria como o excesso de riqueza podem despertar uma disposição de ânimo contra o estado de direito: "Der reiche Pöbel (ist) atomisiert, entfremdet, entbindet, desintegriert. Er setzt sich als atomisierter Einzelner als das Allgemeine, entfremdet dieses damit in die Form der bloßen Partikularität, entbindet sich von ihm und desintegriert damit die Logik des sittlichen Gemeinwesens als solche."

\begin{tabular}{|l|l|l|l|l|}
\hline Q Povista Dialectus & Ano 9 & n. 18 & Outubro 2020 & p. 365-389 \\
\hline
\end{tabular}


res. Para Hegel, os indivíduos estão repartidos em "sistemas particulares de carência", com meios e trabalhos próprios e com modos de satisfação e formação teórica e prática correspon$\operatorname{dentes}^{13}(\mathrm{GW} 14,1: \S 201)$.

Se por um lado a escolha por um determinado trabalho tem a influência de "disposições naturais", do "nascimento" e das "circunstâncias", por outro lado "a determinação última e essencial reside na opinião subjetiva e no arbítrio particular", ou seja, o vínculo a uma determinada profissão e instituição social correspondente é "mediado pelo arbítrio e tem para a consciência subjetiva a figura de uma obra de sua vontade." (GW 14,1: § 206) Dentro das instituições sociais (ou corporações) vem à existência a formação de um "elemento comum", ou seja, uma forma de vida compartilhada. O membro de uma instituição social desenvolve um "fim egoísta" que é, ao mesmo tempo, universal. (1) Egoísta porque diz respeito à defesa de interesses e de uma forma de vida particular da instituição social da qual o indivíduo é membro. (2) Universal porque o fim ou o interesse formado coletivamente dentro dessa instituição social é "inteiramente concreto e não tem nenhuma amplitude maior do que a que reside na [respectiva] indústria, na sua ocupação peculiar e no interesse próprio." ${ }^{\text {"4 }}$ (GW 14,1: § 251) Se por um lado a instituição social precisa ser reconhecida pelo poder público, por outro ela tem a autonomia tanto para "cuidar de seus próprios interesses incluídos no seu interior", assim como para "tomar a seu cuidado os seus integrantes em face das contingências particulares" e para "cuidar da formação da sua capacidade". É por isso que Hegel caracteriza as instituições sociais como uma "segunda família" (GW 14,1: § 252), no sentido de que o seu membro tem nela (1) um "solo firme, enquanto garantia da subsistência condicionada pela capacitação", e (2) o momento do reconhecimento, pois, por meio de uma instituição social, “está também reconhecido que ele pertence a um todo, que ele próprio é um elo da sociedade universal"15 (GW 14,1: § 253). A forma de vida e a práxis compartilhada dentro da instituição

13 É nesse sentido que Kervégen (2007, p. 369) afirma que as instituições sociais formam um horizonte de sentido para os seus membros: "[...] les institutions sont de purs rapports symboliques qui structurent la perception, l'énonciation et l'action de sujets, lesquels n'accèdent au status de sujets que pour autant qu'ils accomplissent les rites qui marquent leur appartenance à l'institution, en même temps qu'ils confèrent à celle-ci la seule réalité - une réalité symbolique, autrement dit subjective-objective - dont elle est susceptible."

14 Os estamentos e corporações, na definição hegeliana, criam formas de vida particulares, com uma práxis coletiva própria, no sentido dado por Jaeggi (2014, p. 77): "Eine Lebensform hat man nicht als Einzelner oder Einzelne. Sie beruht auf sozial geteilten Praktiken, selbst da, wo man als Einzelner an diesen teilhaft und sich zu diesen verhält. Die Lebensform eines Individuums bezeichnet die Hinsicht, in der es als einzelnes und in seinem individuellen Handeln Anteil an einer kollektiven Praxis hat."

15 "What is recognized in these social roles is the ability to contribute something useful to the social whole, but also the particular abilities of individuals; the recognition also comprises, in a sense, their decision to chose

\begin{tabular}{|c|c|c|c|c|}
\hline Rovista Dialectus & Ano 9 & n. 18 & Outubro 2020 & p. $365-389$ \\
\hline
\end{tabular}


social são os freios socialmente constituídos ao luxo e ao esbanjamento das "classes empreendedoras", já que o indivíduo, "reduzido pelo seu isolamento ao lado egoísta", procurará "alcançar o seu reconhecimento por meio de demonstrações exteriores do seu sucesso na indústria, demonstrações que não têm limites, porque não há como viver conforme ao seu estamento quando ele não existe". Desse modo, são estabelecidos dentro das instituições sociais critérios normativos não apenas para um padrão de consumo, mas também uma condição básica para uma forma de vida particular reconhecida socialmente, de modo que "a ajuda que a pobreza recebe perde o seu caráter contingente, assim como o seu caráter injustamente humilhante". Enquanto o vínculo a uma forma de vida compartilhada produz uma certa "retidão" (Rechtschaffenheit) no comportamento individual, o reconhecimento social é responsável pela geração de uma certa autoestima (ou honra) de pertencer a um determinado agrupamento social $^{16}$ (GW 14,1: § 253 A.). Ao dar um caráter formativo, socialmente compartilhado, para a práxis individual, a instituição social eleva esta a uma "atividade consciente em vista de um fim comum", fornecendo uma outra base para a ação além da mera opinião individual contingente $^{17}(\mathrm{GW} 14,1: \S 254)$.

A separação entre sociedade civil burguesa e Estado se apresenta, de um lado, como a "particularidade refletida dentro de si da carência e da fruição" e, de outro, como a "universalidade jurídica abstrata" do código civil burguês (GW 14,1: § 255; cf. § 209-229) ao lado dos instrumentos de administração e regulação da economia capitalista (cf. GW 14,1: $\S 231-249)$. Os dois momentos estão unidos de "maneira interior" quando o "bem-estar particular" é efetivado enquanto direito (GW 14,1: § 255). Essa união interior nada mais é do que

this kind of profession, and hence their free will. Hegel says that the individual's 'arbitrary will' wins 'right... merit, and... dignity' in civil society, and one form that this dignity takes is to be recognized as a particular somebody, who has chosen this profession for himself of herself an now excels in it." (HERZOG, 2013, p. 78)

16 O mundo salarial do pós-guerra, orientado pelo principio dos direitos sociais, conheceu essa dinâmica, principalmente, nas instituições da classe despossuída: “[...] on comprend que l'acceptation du salariat à part entire représente une étape décisive de la promotion de la modernité: un modèle de société dans lequel les positions sociales sont essentiellement définies par la place occupée dans la division du travail." (CASTEL, 1995, p. 314)

17 Herzog (2019, p. 35) faz uma observação interessante sobre essa retidão do comportamento individual vinculado a uma forma de vida particular. Trata-se de um outro modelo, menos sujeito às análises de preferência individual desenvolvidas pela economia comportamental, pois ele tem como enfoque a formação de um padrão social de comportamento: "Esse é um tratamento bem diferente daquele observado por economistas sobre como padrões gerais de comportamento são introduzidos no mercado. Ele não surge de uma consequência de como as preferências estáticas das pessoas se relacionam mutuamente, mas diz respeito à formação dessas mesmas preferências: estas se tornam padronizadas, e, como as corporações são comunidades éticas, também 'eticizadas'. O que Hegel faz na teoria das corporações é transformar as instituições sociais nas quais preferências e identidades dos indivíduos são formadas em um objeto explícito de teorização.”

\begin{tabular}{|c|c|c|c|c|}
\hline Rovista Dialectus & Ano 9 & n. 18 & Outubro 2020 & p. 365-389 \\
\hline
\end{tabular}


a disposição de ânimo (Gesinnung) para o estado de direito, sobre a qual, entretanto, o Estado não tem qualquer controle. Ela é a "confiança $[. .$.$] de que o meu interesse substancial e parti-$ cular está conservado e contido no interesse e no fim [...] do Estado”. Por um lado, ela é ativada por um agir individual conforme às práticas socialmente partilhadas nas instituições sociais; por outro, ela é o resultado das instituições reconhecidas pelo Estado (GW 14,1: § 267). Desse modo, as instituições sociais formam "a racionalidade desenvolvida e efetivada no âmbito do particular", no sentido de que "nelas a liberdade particular está realizada e é racional", ou seja, o bem-estar particular é realizado como direito. Ao contrário da interpretação comum de que a ideia hegeliana de Estado concede aos cidadãos pouco espaço de decisão e controle político, Hegel defende que a constituição é racional apenas quando está assentada sobre a base das liberdades particulares: as instituições sociais "formam as constituição, [...] a base sólida do Estado [...] e são os pilares da liberdade pública” (GW 14,1: § 265).

O "desenvolvimento ulterior" dessa constituição é de responsabilidade do poder legislativo (GW 14,1: § 298). A representação política atua como um "órgão mediador" que impede que os interesses particulares das instituições sociais se isolem em relação ao Estado (GW 14,1: § 302). Marx criticou o fato de que, segundo a ideia hegeliana de Estado, a instituição social "atinge uma significação e uma atuação política" apenas dentro do poder legislativo $^{18}$ (cf. MEGA I,2: p. 77). Contudo, é apenas por meio da separação entre o desenvolvimento autônomo dos interesses sociais e a formação do interesse comum político que se pode “deixar o princípio da subjetividade completar-se até o extremo autônomo da particularidade pessoal" (GW 14,1: § 260). Sem essa separação não há, portanto, autonomia das instituições sociais frente ao Estado. Por isso, as instituições sociais só podem intervir no poder legislativo por meio de deputados (GW 14,1: § 308). Hegel defende uma deputação provinda de assembleias das instituições sociais, isto é, não por meio do voto direito. Sua justificativa é que a sociedade civil elege os seus deputados a partir do que ela é, ou seja, "não enquanto dissolvida atomisticamente nos singulares", reunindo-se apenas "por um instante sem sustentação ulterior, para um ato isolado e temporário", mas sim enquanto "articulada" em instituições sociais (GW 14,1: § 308). A ideia do Estado concreto se apresenta, assim, como um "todo articulado em seus círculos particulares" (GW 14,1: § 308 A.).

18 No caso do manuscrito de Marx Zur Kritik der hegelschen Rechtsphilosophie (MEGA I,2: p. 3-137), eu utilizo, eventualmente com modificações, a tradução de Rubens Enderle e Leonardo de Deus. Cf. MARX, K. Crítica da filosofia do direito. São Paulo: Boitempo, 2005. As outras traduções de textos de Marx são de minha autoria.

\begin{tabular}{|l|l|l|l|l|}
\hline Rovista Dialectus & Ano 9 & n. 18 & Outubro 2020 & p. 365-389 \\
\hline
\end{tabular}


A separação entre sociedade civil e Estado - e, mais especificamente, entre o livre desenvolvimento dos interesses sociais e a sua significação e atuação política - não é livre de contradições. Por um lado, a deputação tem o sentido de que "os deputados estejam familiarizados com as carências especiais, os obstáculos, os interesses particulares desta e os compartilhem.” (GW 14,1: § 311) Por outro, a delegação tem também o sentido de que os deputados entendem melhor dos assuntos políticos do que os que delegam e façam valer não o interesse particular de uma instituição social contra o interesse político geral, mas sim, essencialmente, este último (GW 14,1: § 309). Por um lado, sociedade civil burguesa e Estado estão unidos "de maneira interior", por meio da disposição de animo política, formada a partir do reconhecimento do bem-estar particular como direito (GW 14,1: § 255). Por outro, enquanto direito da liberdade subjetiva, a "esfera da interioridade [...] não constitui domínio do Estado." (GW 14,1: $§ 270$ A.) Para Hegel, cada uma das esferas do direito - direito privado, moralidade, família, sociedade civil e Estado - tem o seu direito próprio, pois todas se apresentam como "ser-aí da liberdade" e, por isso, "estão no mesmo plano de serem direitos", podendo entrar em colisão entre si (GW 14,1: $§ 30$ A.). A ideia de Estado ético fornece apenas a forma racional em que as contradições sociais e políticas podem se desenvolver enquanto luta por direitos. ${ }^{19} \mathrm{O}$ que acontece então quando uma camada da sociedade civil burguesa não está organizada em instituições sociais? Assinalaria a plebe um ponto de "contingência radicalmente subjetiva" em que a filosofia social de Hegel fracassa em sua tarefa de conceituar o político? ${ }^{20}$

\section{A resposta de Marx à questão social e constitucional no Vormärz}

A crítica de Marx foi feita mais de 20 anos após Hegel ter escrito as Linhas fundamentais da filosofia do direito. O prefácio de Hegel é de 1820; o manuscrito de Marx, conhecido como Crítica da filosofia do direito de Hegel, é de 1843. Nesse sentido, ao contrário de Ruda, considero importante levar em conta a dimensão histórica sobre o que Hegel e Marx

19 "Das Abbrechen der metaphysischen Spitze bedeutet hier, daß diejenige Instanz verschwindet, die den Inhalt der Entwicklung des Rechts als fortschreitende Konkretisierung der Freiheit garantieren könnte. Und das bedeutet weiter, daß die Kollisionen in der endlichen Wirklichkeit ihre Verlaufsformen und Lösungen in dieser selbst finden müssen, was in letzten Konsequenz heißt: diese Widersprüche sind anders zu begreifen als in der Hegelschen Logik." (ARNDT, 1995, p. 91)

20 "Wenn Hegel das, was ist, adäquat beschreibt, dann lässt sich behaupten, dass Marx - der Denker der 'wirklichen Verhältnisse' - an genau der Stelle ansetzt, an der Hegel scheitert. Dass Marx zur Notwendigkeit der Transformation der Philosophie und ihrer Kategorien durch das Hegel'sche Scheitern getrieben wurde, bedeutet, dass sich der Pöbel - das Problem, an dem Hegels 'politische Philosophie' scheitert - als Ausgangspunkt des Marx’schen Unternehmens verstehen lässt.” (RUDA, 2011, p. 24; cf. p. 184)

\begin{tabular}{|l|l|l|l|l|}
\hline Q Povista Dialectus & Ano 9 & n. 18 & Outubro 2020 & p. 365-389 \\
\hline
\end{tabular}


tomam por "o que é". Para Ruda, a "emergência da plebe" se apoia em uma "contingência

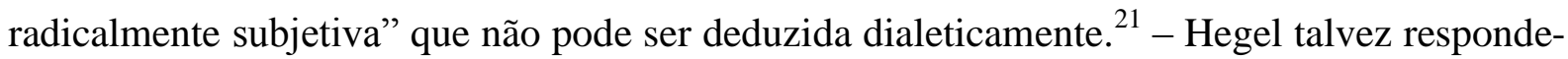
ria que a mera contingência é uma categoria lógica que se contradiz em si mesma, pois o que é contingente está desde o começo em relação com um outro que não é contingente. Já quando afirmamos que algo é contingente, estamos diante de uma contradição, pois ser é a igualdade simples consigo mesma, enquanto a contingência é o que é simplesmente desigual e negativo. Portanto, afirmar uma contingência é já passar ao seu outro. Como esse outro surge da própria afirmação da contingência, não é possível afirmar que se trata de uma necessidade exterior. Para o senso comum, o que é contingente se apresenta como algo positivo, como um fato, ou seja, como algo que tem realidade (GW 18: p. 284 et seq.). Contextualizar um fato filosoficamente significa apreende-lo em sua necessidade lógico-conceitual. A tarefa da filosofia do direito é conceituar o princípio moderno da liberdade subjetiva não como algo contingente, mas sim em sua necessidade (GW 14,1: p. 16). - A pergunta sobre “o que é”, era, para Hegel em 1820, uma sociedade civil burguesa "articulada nas suas corporações, comunas e associações cooperativas de todo modo já constituídas, que dessa maneira adquirem uma conexão política.” (GW 14,1: § 308) Para o jovem Marx em 1843, o que é, é agora uma sociedade civil burguesa "dissolvida atomisticamente nos singulares" e que queria se reunir "somente por um instante sem a sustentação ulterior, para um ato isolado e temporário" (cf. MEGA I,2: p. 121; GW 14,1: § 308).

Entre 1820 e 1843, a Prússia conheceu os efeitos de uma política de reformas liberais no campo econômico, responsável pelo aguçamento da questão social. ${ }^{22}$ A desagregação da ordem estamental criou uma sociedade dissolvida atomisticamente em singulares que via no voto democrático a única forma de poder tomar parte nos assuntos políticos. Por isso, Koselleck (1989, p. 389) afirma que a crítica de Marx dispõe de uma experiência histórica que Hegel não pôde ter. Se por um lado a sua crítica se dá no mesmo nível de abstração de Hegel - no âmbito da filosofia do espírito objetivo -, por outro lado as contradições sociais apontadas por Marx se referem a um processo histórico posterior à analise de Hegel. Para Koselleck (1989, p. 390): "Marx deduz logicamente a partir de Hegel e, empiricamente, a

21 "Die Emergenz des Pöbels lässt sich nicht aus der geschichtlichen Bewegung der bürgerlichen Gesellschaft oder des Staates ableiten, da sie allein auf einer radikal subjektiven Kontingenz beruht. Sie markiert denjenigen Punkt, an dem die Ableitung hadert, stockt und etwas Unableitbares, Kontingentes ins Spiel kommt: Der Pöbel markiert einen Punkt der Unmöglichkeit (der deduktiven Herleitung)." (RUDA, 2011, p. 184)

22 "Ein zentrales Thema des Vormärz ist angeschlagen: die Massenarmut, genauer die Staatsunmittelbarkeit der Armut, die sich aus dem Zerfall der Ständeordnung ergab.” (KOSELLECK, 1989, p. 129)

\begin{tabular}{|l|l|l|l|l|}
\hline Rovista Dialectus & Ano 9 & n. 18 & Outubro 2020 & p. 365-389 \\
\hline
\end{tabular}


partir de sua situação”. Enquanto a economia se modernizava após às reformas liberalizantes, a representação política continuava sendo fundamentalmente estamental. ${ }^{23} \mathrm{Com}$ isso, a economia de mercado produzia uma classe de proprietários e não-proprietários como novos atores sociais, mas que, por estarem excluídos do jogo político, se reuniram momentaneamente em torno da reivindicação por uma constituição moderna. ${ }^{24}$ Por isso, na Prússia, a questão social se colocava, ao mesmo tempo, como questão constitucional. ${ }^{25}$ É nesse contexto histórico que se torna possível identificar a existência da plebe pobre, isto é, de uma massa sem qualquer direito e qualquer organização social e que não conhecia limites para a sua penúria. ${ }^{26}$

Este me parece ser o contexto histórico adequado para refletir sobre a resposta de Marx à questão social e constitucional prussiana. - Em relação ao seu procedimento, não há muita diferença em relação ao que a teoria crítica depois foi chamar de critica imanente: "Eu não sou, portanto, a favor de que nós hasteemos uma bandeira dogmática, pelo contrário. Nós temos que tentar ajudar os dogmáticos a esclarecer as suas próprias sentenças." 27 (MEGA I,2: p. 487 et seq.) A filosofia fornece aqui apenas uma gramática para os conflitos e reivindicações sociais já existentes: “A razão sempre existiu, apenas não na forma racional.” (MEGA I,2: p. 487). A “verdade social” deve, então, para Marx, deixar se desenvolver "a partir do conflito do Estado político consigo mesmo". O progresso da forma republicana do Estado está, justamente, em expressar "todos os conflitos sociais, carências, verdade" (MEGA I,2: p. 488). É por isso que o "esforço da efetiva sociedade civil burguesa" vai no sentido de dar a si mesma um "ser-aí político" (MEGA I,2: p. 128). O voto democrático "forma o interesse político principal da efetiva sociedade burguesa" (MEGA I,2: p. 130), pois ele se apresentava, na época, como a única forma de incluir as novas classes proprietária e não-proprietária no processo de formação da vontade política.

23 "Die Stände wurden zu wirtschaftlichen Interessenvertretungen gestempelt, und auch dies nur in einem einschränkenden Sinne, indem die Vertreter der Fabriken, der Banken, des Handels und der Juristen nur als Grundbesitzer auftreten sollten.” (KOSELLECK, 1989, p. 342)

24 "So konnte die Revolution ausbrechen, in der sich die Großbürger und Fabrikanten zunächst auf derselben Seite befanden wie die Kleinbürger und Arbeiterklassen, die ihrerseits Schutz gegen eben jene Unternehmer vergeblich vom Staat forderten.” (KOSELLECK, 1989, p. 637)

25 "Wie das Proletariat zugleich mit dem neuen Wirtschaftsbürgertum entstanden war, so stellte sich in Preußen die soziale Frage zugleich als Verfassungsfrage." (KOSELLECK, 1989, p. 620)

26 " Es war eine Klasse, die nach oben keine geschlossene Standesgrenze, nach unten keine Grenze der Not kannte. Sie war noch auf das platte Land angewiesen, aber nicht mehr daran gebunden, sie ginge über in die städtische Unterschicht, bevölkerte den freien Arbeitsmarkt und war, politisch ohne Rechte oder gar Organisation, von den Unternehmern aller Art in Stadt und Land abhängig.” (KOSELLECK, 1989, p. 556)

27 'Immanente Kritik tritt dann wie Marx sagt, 'nicht mit einem vorgefertigten Ideal der Wirklichkeit entgegen', sie entnimmt es ihr aber auch nicht einfach, sondern entwickelt dieses Ideal aus dem widersprüchlichen 'Bewegungsmuster der Wirklichkeit' selbst." (JAEGGI, 2009, p. 286)

\begin{tabular}{|l|l|l|l|l|}
\hline Rovista Dialectus & Ano 9 & n. 18 & Outubro 2020 & p. 365-389 \\
\hline
\end{tabular}


A dupla mediação do político entre instituições sociais e representação política pressupõe a existência de liberdades civis burguesas, como a liberdade de imprensa e liberdade de associação, algo que a Prússia ainda não conhecia em sua amplitude. Mais interessante e atual do que as respostas revolucionárias de Marx à questão social me parece ser a sua reivindicação do "direito consuetudinário" (Gewohnheitsrecht) da classe despossuída enquanto um "direito legal” (gesetzliches Recht): "Nós reivindicamos à pobreza o direito consuetudinário, mais especificamente um direito consuetudinário que não é local, um direito consuetudinário que é o direito consuetudinário da pobreza em todos os países.” (MEGA I,1: p. 204) Assim como Hegel, e contra a Escola histórica do direito, Marx era a favor da codificação das leis (cf. MEGA I,1: p. 191-198). Por isso, a forma de vida da classe despossuída, com o seu livre acesso aos seus meios habituais de vida, deveria ganhar a forma de um direito legal: "No tempo das leis gerais (allgemeiner Gesetze), o direito consuetudinário racional não é nada mais que o hábito do direito legal, pois o direito não deixou de ser hábito porque ele se constituiu como lei, mas ele deixou de ser apenas hábito.” (MEGA I,1: p. 206) Marx vê na forma de vida habitual da classe despossuída não uma disposição de ânimo contra o direito, mas, pelo contrário, um "sentido instintivo de direito" (instinktmäßiger Rechtssinn) (MEGA I,1: p. 209) e o sentimento da carência de "satisfazer um impulso jurídico" (einen rechtlichen Trieb zu befriedigen) (MEGA I,1: p. 208). Contra a lei que tornava propriedade privada o acesso à lenha, Marx trazia a ideia hegeliana de Estado: “Toda a nossa apresentação mostrou como a câmara dos deputados (Landtag) [...] degrada a ideia de Estado a meios materiais de interesses privados.” (MEGA I,1: p. 232) Ou seja, contra a hegemonização dentro da esfera política por interesses econômicos advindos da esfera do direito privado, Marx defendeu o direito particular da classe despossuída aos seus meios de vida: "todos os direitos consuetudinários dos pobres se baseavam no fato de que certa propriedade porta um caráter oscilante que não é selado decisivamente como propriedade privada nem como propriedade comunal, uma mistura de direito privado e direito público” (MEGA I,1: p. 207).

A mesma mistura entre direito privado e direito público da ideia marxiana do direito social está, ao meu ver, presente nos sistemas de proteção social dos Estados sociais. ${ }^{28} \mathrm{O}$

28 'L'État social trouve là une fonction spécifique. Il es, pourrait-on dire, le garant de la propriété de transfert. L'État se taille ainsi un rôle nouveau et complètement original qui lui permet de surplomber l'antagonisme absolu entre la défense éperdue de la propriété ,bourgeoise“ et les programmes socialistes visant son appropriation. Il peut jouer ce rôle sans attenter à la propriété privée. Mais, par la gestion de la propriété de transfert, il lui superpose un système de prestations publique qui assure la sécurité sociale." (CASTEL, 1995, p. 316).

\begin{tabular}{|c|c|c|c|c|}
\hline Rovista Dialectus & Ano 9 & n. 18 & Outubro 2020 & p. 365-389 \\
\hline
\end{tabular}


direito social pode ser definido então como o ser-aí da liberdade diante dos riscos de existência causados pela dinâmica capitalista de mercado. Ele é a resposta mais racional até agora desenvolvida à questão social moderna. Por meio dele, o bem-estar particular da classe despossuída é reconhecido e efetivado como direito. O reconhecimento forma, ao meu ver, a verdadeira passagem da plebe ao proletariado, enquanto classe despossuída incluída na lógica de reconhecimento da ideia de Estado ético: “O direito não depende mais da contingência do hábito [ser] racional, mas sim o hábito se torna racional porque o direito é legal, porque o hábito se tornou hábito do Estado.” (MEGA I,1: p. 206) Por esse meio, o Estado social fornece a base para que a classe despossuída possa formar uma disposição de ânimo política a seu favor. Isso implica, certamente, em uma inclusão dos interesses particulares da classe despossuída no debate político, o que, por sua vez, pressupõe historicamente o surgimento das instituições sociais onde a classe despossuída pudesse formar os seus próprios interesses e ter a representação política destes. ${ }^{29}$ É a forma republicana do Estado que vai permitir o desenvolvimento dessa dinâmica. Esta, porém, não é livre de contradições.

\section{A contradição da democracia representativa}

Ao permitir a extensão do debate político a toda sociedade civil burguesa, a democracia representativa realizou, em parte, aquilo que o jovem Marx via como o desdobramento do processo revolucionário na França. O papel da emancipação deveria se desenvolver em "série" até finalmente alcançar a classe social que quer organizar "todas as condições da existência humana sob a pressuposição da liberdade social". A "emancipação parcial” (política) seria, assim, o "fundamento" da emancipação "universal” (social) (MEGA I,2: p. 181). Pelo menos no caso dos Estados sociais europeus, foi a emancipação política que possibilitou a inclusão dos interesses da classe despossuída na formação da vontade política geral. Em oposição aos interesses econômicos e enquanto foi um princípio dominante na história mundial, a reivindicação por direitos sociais podia influenciar a organização das condições de existência humana.

Não era intenção de Hegel procurar por nenhuma solução harmônica ou definitiva para as contradições sociais e políticas. Se por um lado a sociedade civil burguesa é o espaço

29 "Certes les ouvriers, travaillés par la propagande républicaine, ont progressivement fait leur la revendication politique du suffrage universel. Mais surtout ils ont eux-mêmes élaboré leur revendication spécifique [...].” (CASTEL, 1995, p. 271).

\begin{tabular}{|l|l|l|l|l|}
\hline Q Povista Dialectus & Ano 9 & n. 18 & Outubro 2020 & p. 365-389 \\
\hline
\end{tabular}


institucional onde o princípio da subjetividade pode desenvolver-se até o "extremo autônomo da particularidade pessoal” (GW 14,1: § 260), por outro lado, essa autodiferenciação dos interesses sociais faz da sociedade civil "o campo de batalha do interesse privado individual de todos contra todos, [...] do interesse privado com os assuntos particulares comunitários, e o desses junto com aquele contra os pontos de vista e os ordenamentos superiores do Estado." (GW 14,1: § 289 A.) Ou seja, há pelo menos três níveis de conflitos: (1) entre os interesses individuais privados, (2) entre os interesses privados e os interesses particulares comunitários formados nas instituições sociais e (3) entre os interesses privados e das instituições sociais contra o ponto de vista do Estado. Como cada uma dessas esferas é um ser um ser-aí da liberdade, todas elas têm o seu direito e estão no mesmo plano, podendo entrar em colisão uma com as outras (GW 14,1: § 30). Por meio das instituições sociais, contudo, o indivíduo se distancia da contingência de uma opinião subjetiva em vista de um interesse particular formado comunitariamente dentro da instituição social (GW 14,1: § 254). Por sua vez, a representação política impede que a vontade política geral seja formada a partir de dois extremos isolados. Por meio dela, nem os interesses sociais se isolam e nem o Estado aparece como "mero poder dominador e arbitrário" (GW 14,1: § 302). Por isso, Hegel conclui que "o membro do Estado é o membro de um tal estamento, somente nessa determinação objetiva ele pode ser tomado em consideração no Estado.” (GW 14,1: § 308 A.) - De um ponto de vista histórico, no Vormärz, essa representação estamental se tornou incompatível com as demandas de participação política dos novos atores sociais proprietários e não-proprietários.

Se por um lado foi a democracia representativa que condicionou o processo de realização de liberdades sociais, em sua forma racional como direitos sociais, foi, por outro lado, ela mesma que minou a continuidade desse processo. Este se desenvolve por meio da dupla mediação do político entre instituições sociais e representação política no poder legislativo. A democracia representativa tem, porém, o voto individual como ponto de partida do processo de formação da vontade política. Para Hegel, a "representação" (Vorstellung) democrática "se detém na determinação abstrata de ser membro do Estado" (GW 14,1: § 308 A.). Ela abstrai, precisamente, das instituições sociais mediadoras enquanto espaço de formação coletiva dos interesses sociais. Sem essa mediação, por um lado, o indivíduo está imediatamente ligado à esfera política e, por outro lado, os poderes do Estado estão diante do perigo de se tornarem propriedade privada. Isso porque a vontade particular se torna a "instância última de decisão", fazendo da constituição o espaço de uma "capitulação eleitoral” (GW 14,1: § 281 A.).

\begin{tabular}{|l|l|l|l|l|}
\hline Q Povista Dialectus & Ano 9 & n. 18 & Outubro 2020 & p. 365-389 \\
\hline
\end{tabular}


Do ponto de vista dos interesses econômicos, Hegel via um progresso no princípio da liberdade da propriedade privada. Para ele, "o novo sistema da liberdade burguesa" contém "liberdade racional, segundo o seu conteúdo". O conteúdo está, justamente, em seu "sentido limitado", isto é, como "liberdade da propriedade, da habilidade, e do que é produzido através destas". O conteúdo racional da liberdade econômica está, precisamente, em deixar se limitar à esfera do direito privado e à dinâmica da sociedade civil burguesa: "nesta esfera esse conteúdo é racional.” (GW 27,1: p. 440) Em suma, o conteúdo racional da liberdade econômica consiste em não ter nenhuma determinação política. Do ponto de vista da opinião pública, Hegel via a "contradição consigo mesma aí presente" (GW 14,1: § 316), pois, por um lado, ela "contém dentro de si os princípios substanciais eternos da justiça, o verdadeiro conteúdo e o resultado de toda a constituição, da legislação e da condição universal”, mas, por outro lado, intervém nela "toda a contingência da opinião, a sua ignorância e a sua perversão, o seu conhecimento e os seus juízos falsos" (GW 14,1: § 317). Por isso, Hegel defendia que a "opinião pública merece ser tanto respeitada quanto desprezada" (GW 14,1: § 318). A liberdade de opinião tem de permanecer um direito formal ( $\mathrm{GW} 14,1$ : $§ 314)$, no sentido de que a opinião pública não pode ser, para Hegel, a fonte imediata das leis: “o Estado não pode reconhecer a consciência moral na sua forma peculiar, isto é, enquanto saber subjetivo, como tampouco na ciência tem validade a opinião subjetiva, a asseveração e o apelo a uma opinião subjetiva." (GW 14,1: § 137 A.)

A formação da vontade política geral tem de se dar por meio de um processo institucional cuja base são os interesses particulares coletivamente formados por meio da participação em uma instituição social autônoma. O voto individual se detém, no entanto, na determinação abstrata de ser membro do Estado. Neste ponto, Marx não está em contradição com Hegel: "Para se comportar como cidadão efetivo do Estado, para obter significado e eficácia política, ele tem de sair de sua efetividade burguesa, abstrair-se dela, recolher-se de toda essa organização em sua individualidade". Também para Marx, ao abstrair da função de mediação das instituições sociais, o voto individual tem uma função individualizante que une imediatamente o indivíduo a um coletivo abstrato: "a única existência que ele encontra para a sua cidadania estatal é a sua individualidade pura e nua" (MEGA I,2: p. 86). O voto democrático coloca, assim, o indivíduo em contradição com as instituições sociais onde os interesses particulares podem ser formulados coletivamente: “Apenas em contradição com essas únicas comunidades aí presentes, apenas como indivíduo, ele pode ser cidadão do Estado." A existência política do cidadão está separada dos espaços em que a liberdade subjetiva pode ser pre-

\begin{tabular}{|l|l|l|l|l|}
\hline Govista Dialectus & Ano 9 & n. 18 & Outubro 2020 & p. 365-389 \\
\hline
\end{tabular}


enchida pelo conteúdo concreto de uma práxis coletiva, própria a uma forma de vida particular: "Sua existência como cidadão do Estado é uma existência que se encontra fora das existências comunitárias, que é, portanto, puramente individual." (MEGA I,2: p. 87)

O voto individual e a disposição de ânimo a favor do estado de direito constituem o ponto de partida e chegada de um processo de formação da vontade política geral, que, por sua vez, apenas por meio dos interesses particulares coletivamente formados nas instituições sociais pode se distanciar das peculiaridades arbitrárias da individualidade pessoal. Se por um lado foi a extensão da representação política, por meio do voto individual, a todos os setores da sociedade que permitiu a inclusão dos interesses da classe despossuída por direitos sociais no debate político, por outro lado é essa mesma representação política que abstrai dos espaços mediadores onde a reivindicação por direitos sociais pode ser formulada concretamente a partir de uma forma de vida particular e uma práxis coletiva. Sem esses espaços mediadores, a formação da vontade política está apoiada em apenas dois extremos: a opinião individual e uma política de governo.

\section{A formação do governo populista}

Quando um Estado tem nas instituições sociais da sociedade civil a garantia da racionalidade desenvolvida e efetivada no âmbito do particular, a sua política de governo precisa também estar apoiada na base sólida dos direitos do bem-estar particular. Os interesses sociais formados coletivamente dentro das instituições sociais, assim como os direitos da particularidade já realizados, constituem o ponto de partida para o debate da formação da vontade política geral dentro do poder legislativo e para a formação de uma política de governo. Essa é a base sólida também para que o "espírito" das instituições sociais, engendrado pela "legitimação das esferas particulares", se inverta "dentro de si mesmo, no espírito do Estado, visto que ele tem no Estado o meio da conservação dos fins particulares.” (GW 14,1: $§ 289$ A.) Essa inversão "dentro de si mesmo" revela, porém, o caráter precário da garantia do surgimento da disposição de ânimo a favor do estado de direito, já que o Estado ético não pode ter qualquer controle sobre a formação desses interesses particulares: “esses assuntos [...] são a propriedade privada, e o interesse dessas esferas particulares [...] repousa conjuntamente sobre a confiança dos seus companheiros" de instituição social (GW 14,1: § 288), de modo que "essa esfera própria pode ser considerada como abandonada ao momento da liberdade

\begin{tabular}{|c|c|c|c|c|}
\hline Rovista Dialectus & Ano 9 & n. 18 & Outubro 2020 & p. 365-389 \\
\hline
\end{tabular}


formal, onde o conhecimento, a decisão e a execução próprias do indivíduo, bem como as pequenas paixões e fantasias, têm uma arena para espraiar-se" (GW 14,1: 289 A.).

O problema não reside, contudo, na precariedade da garantia da formação da disposição de ânimo política do indivíduo a favor do estado de direito, mas sim, antes, na possibilidade de uma política de governo não estar ancorada em interesses e direitos particulares. Ou seja, a questão é quando a política de governo não pode conservar as esferas particulares dos cidadãos, simplesmente porque a sociedade civil não está articulada em instituições sociais. Tanto as instituições da soberania, "que atuam de cima para baixo", quanto os "direitos" das instituições sociais, "que atuam de baixo para cima", impedem que o governo assuma "a posição isolada de uma aristocracia e que a cultura e a habilidade se tornem um meio de arbítrio e dominação." (GW 14,1: § 297) Aqui reside o risco de um governo tecnocrático que transforma a administração econômica em instrumento de dominação. ${ }^{30}$ Os interesses econômicos ganham, com isso, uma determinação imediatamente política e perdem o seu conteúdo racional de deixar se limitar à esfera do direito privado. ${ }^{31}$

A ausência de instituições sociais mediadoras, exercendo o controle de baixo para cima sobre o governo, significa não apenas a possibilidade de elevar e hegemonizar interesses econômicos à esfera política. É a esfera do direito privado como um todo que adquire uma determinação política e, com isso, "toda a contingência da opinião" pode se tornar a base para a formação da política de governo. Quando é dada uma determinação política à esfera do direito abstrato, tanto a contingência do senso comum como as formas de sentimento podem ser mobilizadas por um candidato a governo contra a formação tecnocrática de uma política de governo apoiada em interesses econômicos: "a objetividade da qual eu sou afetado não é determinada por mim" (GW 25,1: p. 537). O perseverar em uma forma de sentimento revela que um setor da sociedade está excluído da dinâmica de reconhecimento de direitos particulares: eu sou apenas afetado por uma política econômica e não tenho qualquer poder de determina-

30 Esse é, por exemplo, o diagnóstico crítico de déficit de legitimação democrática que Habermas volta contra a política neoliberal da União Europeia: "Einer demokratisch entwurzelten Technokratie fehlen sowohl die Macht wie das Motiv, die Forderungen der Wahlbevölkerung nach sozialer Gerechtigkeit, Statussicherheit, öffentlichen Dienstleistungen und kollektiven Gütern im Konfliktfall gegenüber den systemischen Erfordernissen von Wettbewerbsfähigkeit und Wirtschaftswachstum ausreichend zu berücksichtigen" (HABERMAS, 2013, p. 92).

31 'On obtient alors la définition néolibérale de l' État de droit' ou du 'règne du droit' (rule of law): ce dernier n'est pas défini par l'obligation du respect des droits de l'homme en général, mais par la limite a priori que le droit privé impose à toute législation comme à tout gouvernement.” (DARDOT; LAVAL, 2016, p. 53) Para Dardot e Laval (2016, p. 56), o Estado neoliberal perde o equilíbrio entre os poderes ao generalizar os interesses da esfera do direito privado: "En définitive, c'est le principe libéral de la 'balance' des pouvoirs qui est sacrifié sur l'autel de la constitutionnalisation du droit privé.".

\begin{tabular}{|l|l|l|l|l|}
\hline Q Revista Dialectus & Ano 9 & n. 18 & Outubro 2020 & p. 365-389 \\
\hline
\end{tabular}


ção sobre ela. - Contra essa situação, o jovem Marx também recorreu à forma subjetiva do sentimento como base de uma ideia de democracia: "Apenas o sentimento [...] pode a partir da sociedade fazer de novo uma sociedade de seres humanos, um Estado democrático." (MEGA I,2: p. 476) Mas, no contexto histórico do Vormärz, a insistência em uma forma de sentimento - aqui o "autossentimento do homem" - era uma forma de se opor ao déficit democrático do Estado prussiano. Poder problematizar um sentimento significa se voltar para o seu conteúdo objetivo: "Eu tenho o sentimento de injustiça, o conteúdo é o direito" (GW 25,1: p. 534). Perseverar em uma forma de sentimento revela, portanto, um bloqueio nesse processo em que o sujeito tematiza objetivamente o conteúdo de seu sentimento. A ausência de liberdades civis burguesas impedia que os novos atores sociais pudessem formular os seus próprios interesses: o sujeito pode se voltar para fora "com interesse" e "com determinada atenção" na medida em que ele "tem um poder em consideração aos objetos" (GW 25,1: p. 540).

Os direitos podem ser sentidos individualmente, mas a forma racional do direito não pode ter uma forma subjetiva de sentimento como sua fonte. Os sentimentos - como o de prazer, alegria, serenidade, dor, medo, esperança, ansiedade, ressentimento e etc. - não têm um conteúdo particular e podem surgir das modificações de um "dado exterior" (äußerlichen Begebenheit) (GW 25,1: § 390). A existência de uma esfera política, que se apresenta como um dado exterior aos indivíduos, denuncia a emergência de uma plebe excluída da dinâmica de reconhecimento do bem-estar particular como um direito legal. Uma política de governo formada a partir da mobilização de formas de sentimento se assenta não na base sólida da racionalidade desenvolvida nas instituições sociais, mas apenas no vazio contingente da opinião e dos afetos da plebe. ${ }^{32}$ A sua disposição de ânimo contra o estado de direito pode ser então mobilizada por um governo contra as instituições da soberania, que exercem o controle de cima para baixo, e contra as instituições sociais, que exercem o controle de baixo para cima. ${ }^{33}$ Ao se legitimar unicamente por meio do voto democrático, a formação da vontade polí-

32 “[... [ surge una visión de la subjetividad política en la cual una pluralidad de prácticas y adhesiones apasionadas entran en un cuadro en el que la racionalidad - ya sea individual o dialógica - ya no es un componente dominante." (LACLAU, 2005, p. 213) Uma visão reduzida de razão se encontra também no populismo defendido por Mouffe: "Vernunft existiert für Mouffe ohnehin lediglich als 'Schleier' vor der eigentlich partikularen, irrationalen, gewaltbegründeten Wirklichkeit.” (ELBE, 2018, p. 111).

33 "Populist leaders seek to use the legitimacy conferred by democratic elections to consolidate power. They claim direct charismatic connection to 'the people,' who are often defined in narrow ethnic terms that exclude big parts of the population. They don't like institutions and seek to undermine the checks and balances that limit a leader's personal power in a modern liberal democracy: courts, the legislature, an independent media, and a nonpartisan bureaucracy." (FUKUYAMA, 2018, p. 8).

\begin{tabular}{|l|l|l|l|l|}
\hline Q Povista Dialectus & Ano 9 & n. 18 & Outubro 2020 & p. 365-389 \\
\hline
\end{tabular}


tica se detém na determinação abstrata e "homogeneizante" de ser membro de um Estado nacional. $^{34}$

Hegel foi criticado por ter dado um tratamento apenas socioeconômico para a questão da plebe. ${ }^{35}$ Ele tinha, no entanto, boa razões para fazer isso. Sua ideia de Estado ético apresenta as condições objetivas para a realização do princípio moderno da liberdade subjetiva: uma constituição assentada sobre os direitos das liberdades particulares, realizados através da dupla mediação do político entre instituições sociais e representação política. A plebe deixa, então, de ser plebe ao estar organizada em instituições sociais e ao poder formular os seus interesses particulares. Incluir politicamente a plebe, sem essa mediação, significa elevar à esfera política o "ponto de vista do negativo em geral". Se para Hegel essa "maneira de ver da plebe" estava fora do poder executivo - pois ela podia apenas pressupor "da parte do governo uma má vontade ou uma vontade menos ruim" (GW 14,1: § 301) -, ela adquire um caráter puramente destrutivo, que se volta contra as instituições da soberania e da sociedade civil, quando se torna base para uma política de governo. Esse ponto de vista do negativo em geral só se encontra consigo mesmo na determinação abstrata de ser membro de um Estado nacional.

\section{Considerações finais}

O populismo atual é o resultado de um processo de dissolução da dupla mediação do político entre instituições sociais e representação política. Por um lado, são as instituições sociais que permitem o desenvolvimento autônomo de interesses particulares, associados a uma forma de vida particular e a uma práxis coletiva. Por outro lado, é a representação política que permite (1) que os interesses particulares possam continuar se reproduzindo autono-

34 "Sin la producción de vacuidad no hay pueblo, no hay populismo, pero tampoco hay democracia." (LACLAU, 2005, p. 213) Contra a lógica da autodiferenciação dos interesses, própria à sociedade civil burguesa, o populismo propõe a sua redução a uma cadeia de equivalência de demandas particulares: "Der Preis für die Konstruktion der 'Äquivalenzkette' (Laclau 1981d, 181) Proletariat = werktätige Massen = antikapitalistisches Kleinbürgertum = mittleres Kapital $=$ ausgebeutete deutsche Nation, ist keineswegs ein die Klassengrenzen transzendierendes herrschaftskritisches Projekt, sondern der zunehmende Bedeutungsverlust der Signifikanten und damit die Abkehr von begrifflich konturierter Kapitalismus- und Faschismusanalyse zugunsten der Bedienung diffuser Ressentiments gegen 'Schieber', 'Spekulanten' und 'Parasiten', teils ‘jüdischer' Art.” (ELBE, 2019, p. 24).

35 "Während ich zu zeigen versucht habe, dass ein genuin wirtschaftliches Problem zu einem politischen wird, scheint der Philosoph selbst diese Argumentation nicht zu teilen: Die Gefahr des Pöbels, vor der er im Abschnitt über die bürgerliche Gesellschaft ausführlich warnt, ist für den Philosophen gebannt." (SCHILDBACH, 2018, p. 193).

\begin{tabular}{|l|l|l|l|l|}
\hline Revista Dialectus & Ano 9 & n. 18 & Outubro 2020 & p. 365-389 \\
\hline
\end{tabular}


mamente, sem uma significação e atuação imediatamente política, e (2) que os interesses particulares possam formar a base para a formação dos interesses gerais.

O reconhecimento e a realização do bem-estar particular como um direito legal não soluciona as contradições da economia de mercado capitalista e nem a contradição entre interesse sociais e políticos. A dupla mediação do político fornece apenas a base para que essas contradições se desenvolvam e possam ser tratadas racionalmente. A plebe é o resultado da dinâmica antagônica da produção da riqueza capitalista. $O$ único tratamento racional para a sua disposição de ânimo anti-institucional passa por uma constituição que ofereça a possibilidade da formulação de seus interesses particulares por meio da sua inclusão na dupla mediação do político. Foi assim que ela se organizou institucionalmente em torno da luta por direitos sociais. Mas ela deixa de ser plebe para ser classe despossuída. Se por um lado a democracia representativa ofereceu a estrutura racional que permitiu essa integração, por outro lado foi ela mesma - ao abstrair das instituições sociais mediadoras - que dissolveu as bases dessa integração.

Sem a mediação de instituições sociais e políticas, a formação da vontade política está apoiada em critérios que veem da esfera do direito abstrato. Estes podem ser tanto (1) os interesses econômicos (neoliberalismo) como (2) a opinião individual contingente ou a maneira de ver da plebe (populismo). A elevação imediata dessa maneira de ver da plebe à política de governo significa dar uma função hegemônica ao seu "significante vazio", ou seja, ao seu ponto de vista do negativo. Demandas particulares precisam ser reduzidas a um "equivalente" - isto é, à determinação abstrata de ser membro de um Estado nacional. Com isso, direitos sociais podem deixar de se apresentar como o resultado do reconhecimento legal de reivindicações das instituições sociais da classe despossuída para receber a determinação abstrata de um Estado nacional: sou membro de um Estado nacional, logo sou portador de determinados direitos sociais. Isso tem um efeito explosivo numa economia de mercado globalizada.

\section{REFERÊECIAS:}

ARNDT, A. Der Begriff der Allgemeinheit in der Philosophie des Rechts. In: HegelJahrbuch 1993/1994. Org. por Andreas Arndt, Karol Bal e Henning Ottmann. Berlin: Akademie, 1995, p. 89-97.

\begin{tabular}{|l|l|l|l|l|}
\hline Qevista Dialectus & Ano 9 & n. 18 & Outubro 2020 & p. 365-389 \\
\hline
\end{tabular}


Zum Philosophischen Arbeitsbegriff: Hegel, Marx \& Co. In: KODALLE, K.-M. (Org.). Arbeit und Lebenssinn. Eine aktuelle Herausforderung in historischer und systematischer Perspektive. Würzburg: Königshausen \& Neumann, 2001. (Kritisches Jahrbuch der Philosophie Beiheft 3/2001), p. 99-108.

CASTEL, R. Les métamorphoses de la question sociale: Une chronique du salariat. Paris: Fayard, 1995.

DARDOT, P.; LAVAL, C. Ce cauchemar qui n'en finit pas. Comment le néolibéralisme défait la démocratie. Paris: La Découverte, 2016.

ELBE, I. Die postmoderne Querfront. Anmerkungen zu Chantal Mouffes Theorie des Politischen. In: Zeitschrift für Ideologiekritik, Heft 12/2018, p. 107-127.

Politische Macht, Faschismus und Ideologie. Ernesto Laclaus Auseinandersetzung mit Nicos Poulantzas. In: Rote-Ruhr-Uni. Disponível em: http://www.rote-ruhr-uni.com/cms/IMG/pdf/poulantzas_und_laclau_langtext.pdf. Acesso em: 28/11/2019.

FUKUYAMA, F. The demand for dignity and the politics of resentments. New York: Macmillan, 2018. (iBook Edition).

HABERMAS, J. Im Sog der Technokratie. Berlin: Suhrkamp, 2013.

HEGEL, G. W. F. Grundlinien der Philosophie des Rechts oder Naturrecht und Staatswissenschaft im Grundrisse. GW 14,1. Hamburg: Meiner, 2009.

. Vorlesungsmanuskripte II (1816-1831). GW 18. Hamburg: Meiner, 1995.

Enzyklopädie der philosophischen Wissenschaften im Grundrisse (1830). GW 20. Hamburg: Meiner, 1992.

. Vorlesungen über die Philosophie des subjektiven Geistes. Nachschriften zu den Kollegien der Jahre 1822 und 1825. GW 25,1. Hamburg: Meiner, 2008.

. Vorlesungen über die Philosophie der Weltgeschichte. Nachschriften zu dem Kolleg des Wintersemesters 1822/23. GW 27,1. Hamburg: Meiner, 2015.

HERZOG, L. Inventing the Market: Smith, Hegel and Political Theory. Oxford: Oxford University Press, 2013.

Duas maneiras de "domar" o mercado: por que Hegel precisa da polícia e das corporações. In: Revista Eletrônica Estudos Hegelianos, ano 16, n. 28, 2019, p. 23-42.

JAEGGI, R. Was ist Ideologiekritik? In: JAEGGI, R.; WESCHE, T. (Org.). Was ist Kritik? Frankfurt/M.: Suhrkamp, 2009, p. 266-295.

Kritik von Lebensformen. Berlin: Suhrkamp, 2014.

\begin{tabular}{|l|l|l|l|l|}
\hline Q Povista Dialectus & Ano 9 & n. 18 & Outubro 2020 & p. 365-389 \\
\hline
\end{tabular}


JAESCHKE, W. Es ist ein Begriff der Freiheit in Religion und Staat. In: ARNDT, A.; IBER, C.; KRUCK, G. (Org.). Staat und Religion in Hegels Rechtsphilosophie. Berlin: Akademie, 2009, p. 9-22.

KERVEGAN, J.-F. L'Effectif et le Rationnel: Hegel et L'esprit objectif. Paris: Vrin, 2007.

KOSELlECK, R. Preußen zwischen Reform und Revolution: Allgemeines Landrecht, Verwaltung und soziale Bewegung von 1791 bis 1848. München: Klett-Cotta, 1989.

LACLAU, E. La razón populista. Buenos Aires: FCE, 2005.

MARX, K. Publizistische Arbeiten. In: Karl Marx: Werke, Artikel, literarische Versuche bis März 1843. MEGA I,1. Berlin: Dietz, 1975, p. 93-366.

. Zur Kritik der Hegelschen Rechtsphilosophie. In: Karl Marx: Werke, Artikel, Entwürfe März 1843 bis 1844. MEGA I,2. Berlin: Dietz, 1982, p. 5-137.

Zur Kritik der Hegelschen Rechtsphilosophie. Einleitung. In: Karl Marx: Werke, Artikel, Entwürfe März 1843 bis 1844. MEGA I,2. Berlin: Dietz, 1982, p. 170183.

. Briefe aus den "Deutsch-Französischen Jahrbüchern". In: Karl Marx: Werke, Artikel, Entwürfe März 1843 bis 1844. MEGA I,2. Berlin: Dietz Verlag, 1982. p. 469-489. Grundrisse der Kritik der politischen Ökonomie. Erster Teil. In: Karl Marx:

Ökonomische Manuskripte 1857/58. MEGA II,1.1. Berlin: Dietz, 1976.

Das Kapital. Kritik der politischen Ökonomie. Erster Band. Hamburg 1890. MEGA II,10. Berlin: Dietz, 1991.

MOUNK, Y. The people vs. democracy: why our freedom is in danger and how to save it. Cambridge; Massachusetts: Harvard University Press, 2018.

NEUHOUSER, F. Foundations of Hegel's social theory: Actualizing Freedom. Cambridge; Massachusetts; London: Harvard University Press, 2000.

RUDA, F. Hegels Pöbel. Eine Untersuchung der "Grundlinien der Philosophie des Rechts". Konstanz: Konstanz University Press, 2011.

SCHILDBACH, I. Armut als Unrecht. Zur Aktualität von Hegels Perspektive auf Selbstverwirklichung, Armut und Sozialstaat. Bielefeld: Transcript, 2018.

\begin{tabular}{|l|l|l|l|l|}
\hline Q Povista Dialectus & Ano 9 & n. 18 & Outubro 2020 & p. 365-389 \\
\hline
\end{tabular}

